\title{
Blood Flow Index and Skin Temperature Measured by Laser Speckle Contrast Imaging and Infrared Thermography After Specific Ultrasound-Guided Blocking of the C6, C7 Nerve Root: A Case Report
}

This article was published in the following Dove Press journal:

Journal of Pain Research

\section{Shuang Zhang \\ Longchang Fan \\ Wei Mei (D)}

Department of Anesthesiology, Tongji Hospital, Tongji Medical College, Huazhong University of Science and Technology, Wuhan, Hubei Province 430030, People's Republic of China
Correspondence: Longchang Fan Department of Anesthesiology, Tongji Hospital, Tongji Medical College, Huazhong University of Science and Technology, Jiefang Ave 1095, Wuhan, Hubei Province 430030, People's Republic of China

Email flc5200@tjh.tjmu.edu.cn

Wei Mei

Department of Anesthesiology, Tongii Hospital, Tongji Medical College, Huazhong University of Science and Technology, Jiefang Ave 1095, Wuhan, Hubei Province 430030, People's Republic of China

Tel + 86- 13006162508

Email wmei@hust.edu.cn

\begin{abstract}
Ultrasound-guided cervical nerve root block is the technique of injecting local anesthetic or steroid into the intertubercular groove outside of the cervical foramen under real-time ultrasound guidance. It has established diagnostic and therapeutic employment for patients suffering symptoms caused by cervical disc disorders and foraminal stenosis. Measures of selective nerve root blockade would have vital clinical utility, especially in multilevel disease or combined with atypical symptoms, where subjective assessment is difficult. This case reported a 47-year-old male patient who suffered from severe radicular pain confined to the index and middle fingers, with weakness of the right upper extremity. $\mathrm{He}$ was successfully treated with selective C6, C7 nerve root under ultrasound guidance. For confirmation of the proper analgesia range, laser speckle contrast imaging (LSCI) and infrared thermography (IT) were both constructed over the dorsum of the hands and forearms during the procedure. The results of the off-line analysis suggested LSCI and IT might be considered as alternative measurements for the selective cervical nerve root.
\end{abstract}

Keywords: selective nerve root block, laser speckle contrast imaging, infrared thermography, ultrasound guidance

\section{Introduction}

Cervical radicular pain, which nearly 1 per 1000 members of the adult population suffer from, ${ }^{1}$ manifests as pain shooting down the corresponding sensory domination areas of the neck or upper limbs. With a progressive water content decline of the intervertebral discs, greater forces are born by lateral disc herniation or foraminal stenosis, resulting in the irritation of cervical spinal nerve roots (CNRs) when exiting from the intervertebral foramen. ${ }^{2}$ Although the clinical syndromes of the neck or upper extremities differ, the irritated nerve roots could explain part of the reason. In addition, the utility and efficacy of therapeutic selective nerve root block (SNR) for cervical radicular pain have been supported. ${ }^{3,4}$ The ultrasound-guided selective cervical nerve root injection was described by Narouze et al in 2009, which was considered an alternative treatment for cervical radiculopathy since then. ${ }^{5}$ Although it was routine to apply the pinprick and cold sensation tests or rely on self-reported pain relief to evaluate the outcomes of nerve root block, these subjective tests are sometimes unreliable or have existing personal bias, particularly in elderly patients with deficient cognitive ability, or those who have abnormal psychology. 
Laser speckle contrast imaging (LSCI) and infrared thermography (IT) are both large-field, noninvasive measurements of perfusion and unbiased by the operator, which show excellent value for skin microcirculation. With high time and space resolution, LSCI, which has been employed in various life science subjects, offers a real-time and contactless evaluation of blood flow over a large field. ${ }^{6,7}$ As for IT, this technique can construct a two-dimensional map on the basis of the temperature differences across regional surfaces of the body. ${ }^{7}$ To the best of our knowledge, there is still no universal standard to measure the effect of SNR on the corresponding dermatome. Firstly, this case was undertaken to assess the therapeutic effect and pain relief after the sequential C7, C6 nerve root block for cervical radicular pain. Then, through the description of the changes in the blood flow index (BFI) and skin temperature (T) in the distal upper limb, we would like to get a glimpse of the feasibility of LSCI and IT to evaluate the clinical outcomes of selective nerve root block.

\section{Case Report}

A 47-year-old male with a more than 2-year history of chronic radicular pain was admitted to our pain department. He complained about the catastrophic pain confined to his right index and middle fingers, with weakness of the right upper extremity. The pain was mainly characterized by a pricking, burning sensation (paresthesia), or electric shock-like pain sometimes. He described his pain as $8 / 10$ based on the VAS. As the pain became progressively worse, there were other symptoms such as irritation and headache. Physical exercise treatment and nonsteroidal anti-inflammatory agents were administered to the patient, yet his pain did not relieve.

\section{Procedure}

The publication of case details was approved by the Ethics Committee of Tongji Hospital, Tongji Medical College (number TJ-IRB20190424). Written informed consent was also provided by the patient before the study commencement. He also signed the agreement on publication of his case details, physical examination results and accompanying images during the procedures.

On arrival in the treatment room, the intravenous access, noninvasive blood pressure and pulse oximetry were established at the lower extremity. The patient's vital signs and the cervical block site were checked over time during and after the treatment to exclude pneumothorax or vascular puncture. Especially, images of both upper limbs were obtained by LSCI and IT cameras.

\section{For Nerve Root Blockade}

The patient was placed in the supine position on the operating table. The head was rotated slightly toward the contralateral side to obtain a better operating condition. A soft pillow was placed beneath the ipsilateral shoulder. The high-frequency probe (SonoSite M-Turbo; SonoSite Inc., Bothell, WA, USA) was placed transversely to the lateral aspect of the neck to obtain a transverse axial view after preparation of the neck skin with povidone-iodine solution. Strict aseptic operations were carried out throughout. In this ultrasonography view, cervical nerve roots could be identified between the posterior and anterior tubercles by moving the transducer either upward or downward, except for the seventh cervical nerve root. The seventh cervical (C7) transverse process was distinguished from the other processes by having a prominent posterior tubercle and a rudimentary anterior tubercle. Since we were unable to figure this small tubercle out in ultrasonography sometimes, the transverse process of $\mathrm{C} 7$ was usually exhibited as a larger posterior tubercle ending in a smooth down-sloping contour anteriorly. Depending on only this sonography feature, the seventh spinal level was readily distinguished from those of the upper consecutive vertebras (Figure 2A). Then, moving the probe cranially, it was easy to visualize the transverse process of the sixth cervical vertebra with its characteristic sharp anterior tubercle and posterior tubercles (Figure 2B). The C7 nerve root appeared as a hyperechoic structure bordered by the isolated posterior tubercle, while the C6 root was a hypoechoic structure held between the posterior and anterior tubercles. Once the appropriate spinal level was identified in the transverse axial view, a 22-gauge needle was slowly advanced toward the target corresponding cervical nerve root with an in-plane technique, from posterior to anterior, under real-time ultrasound guidance. ${ }^{8}$ Once careful aspiration with a syringe did not reveal any blood or cerebrospinal fluid, mixed solution $(2.5 \mathrm{~mL})$ was injected at the two nerve root sites, respectively. This solution was composed of $10 \mathrm{~mL}$ normal saline, $0.15 \mathrm{mg}$ ropivacaine, $0.25 \mathrm{mg}$ mecobalamin and $5 \mathrm{mg}$ dexamethasone. The blockade of the $\mathrm{C} 7$ nerve root was accomplished first, and then the blockade of the C6 nerve root. The procedure flow chart is shown in Figure 1C. 


\section{For Measurements}

Upon arrival, the patient was allowed 20 min to rest comfortably in the supine position to acclimate the surroundings before all the measures. The operating room temperature was maintained at $24{ }^{\circ} \mathrm{C}$. The patient's hands were put on a thermally insulated surface, approximately $45 \mathrm{~cm}$ away from the thermal camera and $30 \mathrm{~cm}$ vertically away from the LSCI camera (Figure 1A). The images of dorsal hands were obtained four times with the LSCI and IT cameras simultaneously. Changes after the $\mathrm{C} 7, \mathrm{C} 6$ nerve root block were imaged simultaneously for $3 \mathrm{~min}$ by LSCI at 20 frames per minute, the same as by IT (ie, contemporaneous image
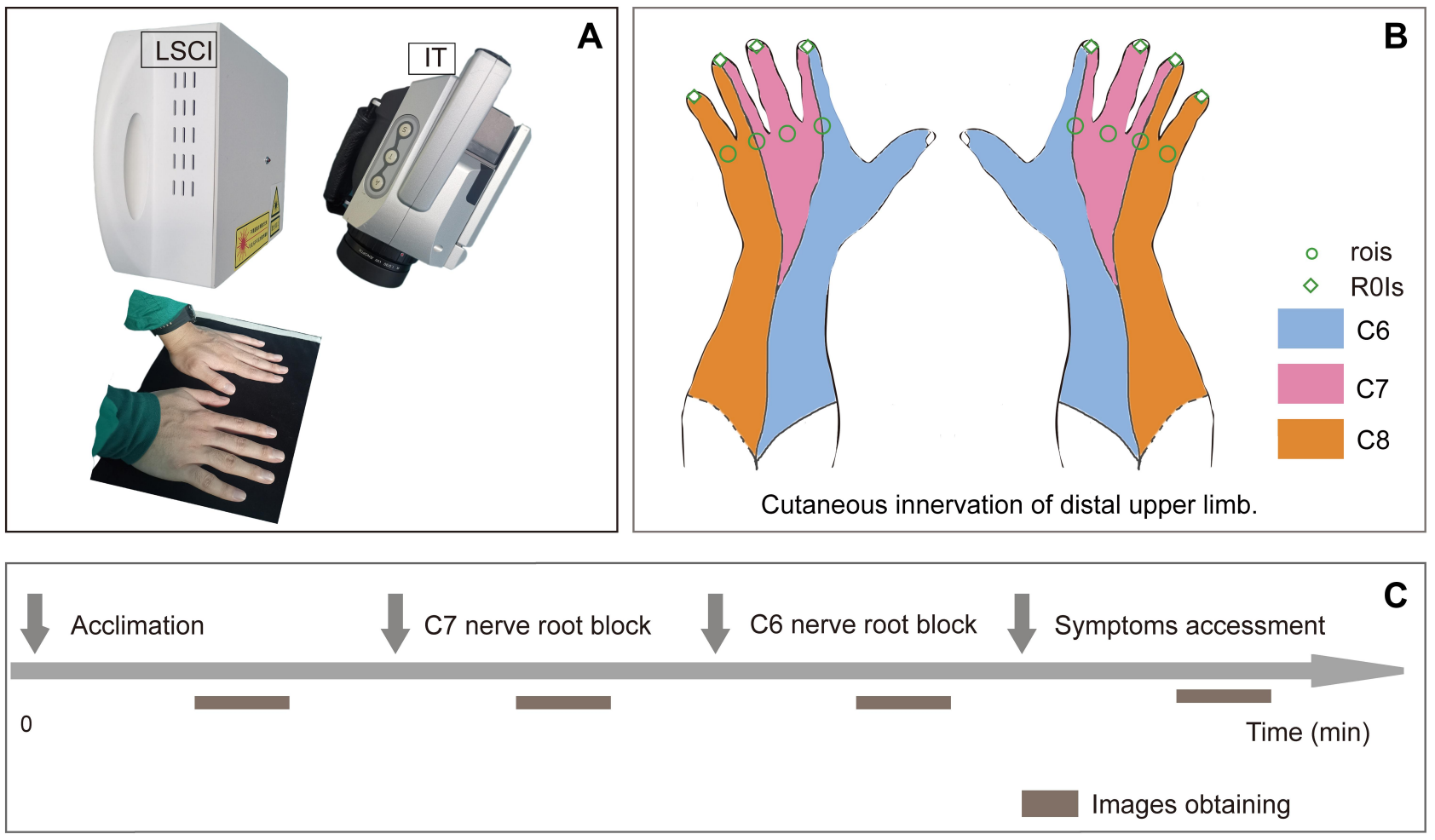

Figure I (A) Photograph of the imaging equipment set up to allow simultaneous imaging, showing laser speckle contrast imaging (LSCI) and infrared thermography (IT). (B) Photograph of the cutaneous innervation of the distal upper limb, showing the regions of interest. ROls, regions of interest performed on the nail bed; rois, regions of interest on skin just proximal to the fingers. (C) Procedure flow chart.
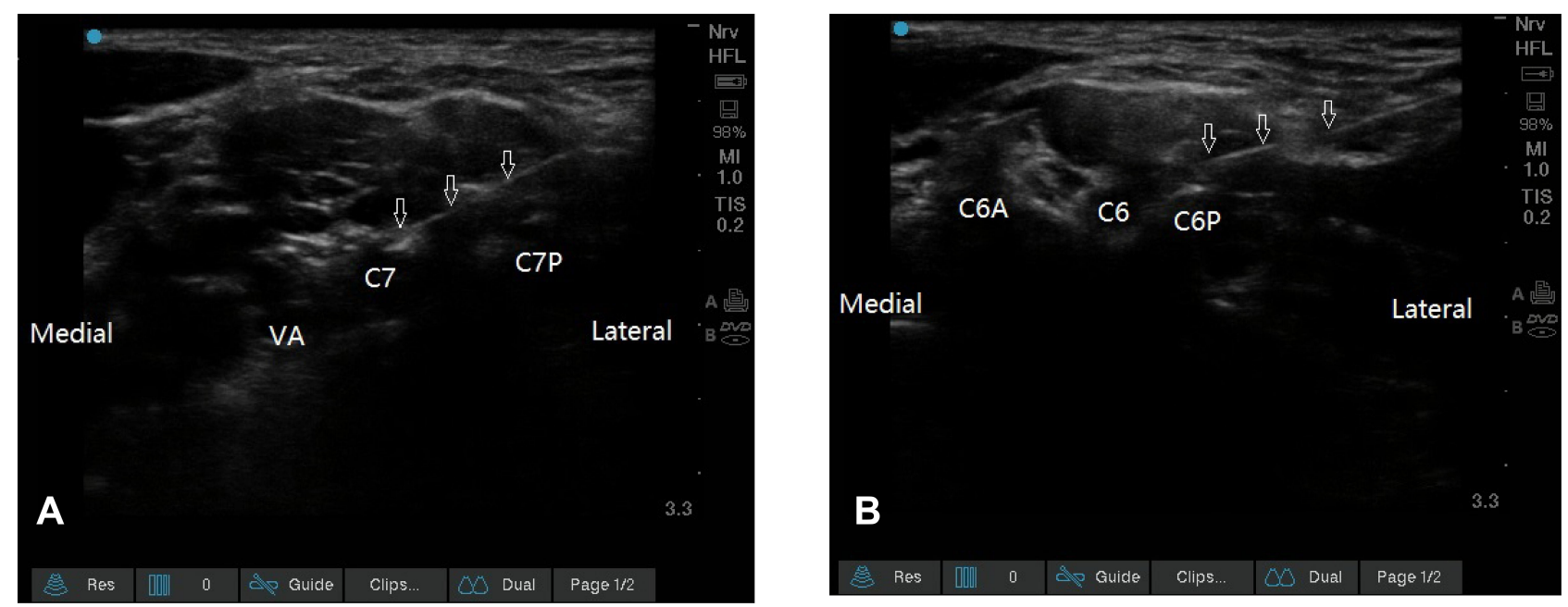

Figure 2 Ultrasound images for the C7 and C6 selective nerve blocks, the needle direction shown by the arrow. (A) C7 selective nerve block. (B) C6 selective nerve block. VA, vertebral artery; C7, the seventh cervical nerve root; C7P, posterior tubercle of the seventh cervical transverse process; C6A, anterior tubercle of the sixth cervical transverse process; C6, the sixth cervical nerve root; C6P, posterior tubercle of the sixth cervical transverse process. 
acquisition for $3 \mathrm{~min}$ every time). Off-line analysis of the images was performed by the laser speckle blood flow imaging system (SIM BFI-WF; SIM Opto-Technology Co., Ltd, Wuhan, China), expressed as perfusion unit (PU), and a selfcontained system (IRBIS ${ }^{\circledR} 3$ plus; InfraTec, GmbH, Germany) for IT in degrees Celsius $\left({ }^{\circ} \mathrm{C}\right)$. Regions of interest were performed on the nail bed of the fingers or skin just proximal to the fingers. $\mathrm{C}_{(\mathrm{ROI})}$, region on the nail bed of the fingers on the contralateral side. $\mathrm{C}_{(\mathrm{roi})}$, region on the skin just proximal to the fingers on the contralateral side. $\mathrm{A}_{(\mathrm{ROI})}$, region on the nail bed of the fingers on the blocked side. $A_{(\text {roi })}$, region on the skin just proximal to the fingers on the blocked side (Figure 1B). We arbitrarily defined the following time points: $t_{0}$, the baseline value ( $3 \mathrm{~min}$ before nerve root block). $\mathrm{t}_{1}, 3 \mathrm{~min}$ after the $\mathrm{C} 7$ block. $\mathrm{t}_{2}, 3 \mathrm{~min}$ after the C6 block. $\mathrm{t}_{3}, 20 \mathrm{~min}$ after all the procedure. The patient's symptoms were also recorded after each image was obtained (Figures $1 \mathrm{C}$ and 3).

\section{Results}

There was no pneumothorax or vascular injury manifestation after 1-hour observation. And the patient got almost complete pain relief and reported no other discomfortable symptoms. He was able to return to his previous full-time work and did not complain of any severe adverse reaction during a 6-month follow up.

Two series of typical diagrams are manifested in Figure 3. The specific blocking of the $\mathrm{C} 7$ nerve root resulted in a substantial increase of the BFI (Figure 4A) and temperature (Figure 4B) in the innervated area (the middle fingertip), and the BFI value of skin proximal to the index finger increased as well. Data in the contralateral did not increase. Similarly, the specific C6 nerve root blockade markedly raised the BFI and temperature in the area innervated by the C6 nerve root (the index finger). In addition, the temperature of the middle fingertip increased by $0.6{ }^{\circ} \mathrm{C}$, and the BFI value of the ring fingertip slightly raised as well. Ultimate analysis $\left(t_{3}\right)$ showed that the BFI value and temperature in ROIs made a noticeable rise on the index and middle fingers with no obvious increase in any other nerve root area of dominance. And a supplementary photograph of

\section{A: Typical diagrams imaged by laser speckle contrast imaging (LSCI)}

Baseline image $\left(\mathrm{t}_{0}\right)$

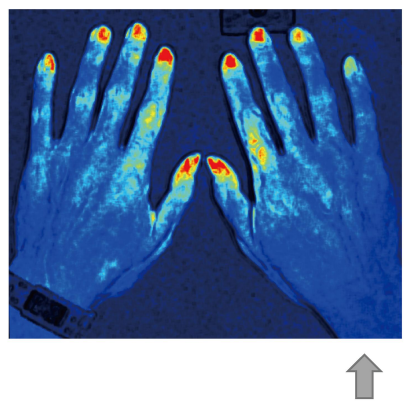

After C7 NB ( $\left.\mathrm{t}_{1}\right)$

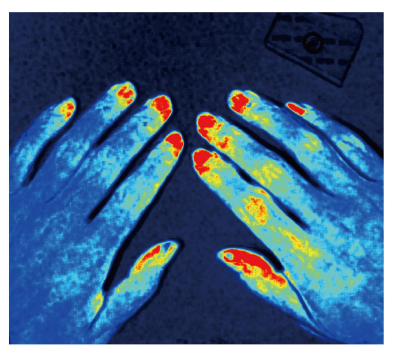

令
After C6 NB ( $\left.\mathrm{t}_{2}\right)$

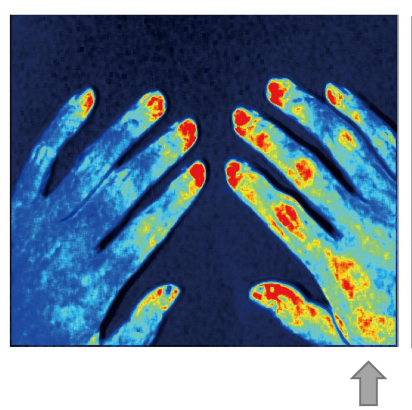

Symptoms accessment ( $\left.t_{3}\right)$

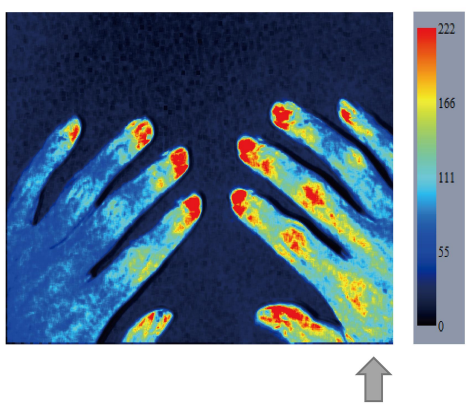

\section{B: Typical diagrams imaged by infrared thermography (IT)}
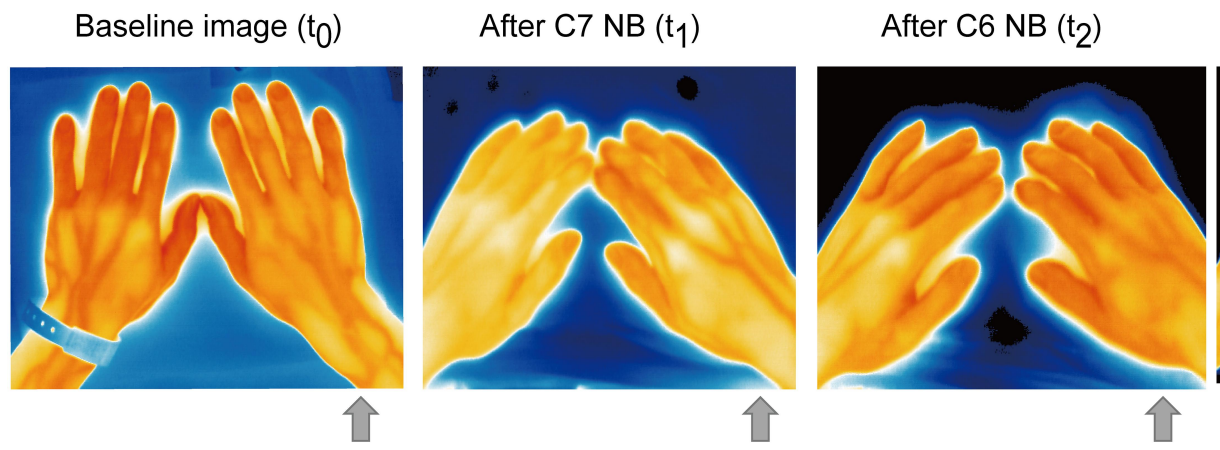

Symptoms accessment $\left(t_{3}\right)$

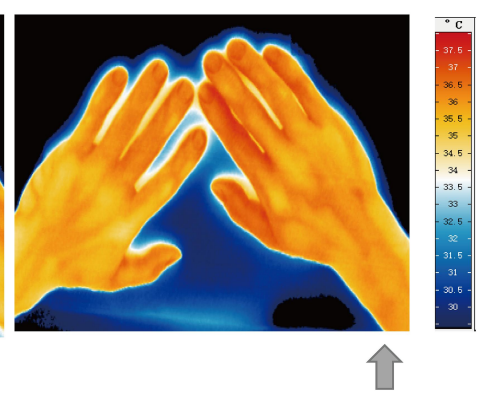

Figure 3 Two series of typical diagrams imaged by laser speckle contrast imaging (LSCI) and infrared thermography (IT), respectively. (A) Dorsal hands imaged by the LSCI at baseline, after C7 nerve block, after C6 nerve block. (B) Dorsal hands imaged by the IT at baseline, after C7 nerve block, after C6 nerve block. 
Table I Results of Reading from Images of Laser Speckle Contrast Imaging and Infrared Thermography

\begin{tabular}{|c|c|c|c|c|c|}
\hline \multirow[t]{2}{*}{ Fingers } & \multirow[t]{2}{*}{ Area } & \multicolumn{4}{|c|}{ Blood Flow Index (PU } \\
\hline & & $\mathbf{t}_{0}$ & $\mathbf{t}_{\mathbf{I}}$ & $\mathbf{t}_{2}$ & $\mathbf{t}_{3}$ \\
\hline \multirow[t]{4}{*}{ The index } & $\mathrm{C}_{(\mathrm{ROI})}$ & 106.4 & 90.25 & 76.21 & 85.86 \\
\hline & $\mathrm{C}_{(\mathrm{roi})}$ & 237.97 & 237.32 & 240.82 & 245.48 \\
\hline & $\mathrm{A}_{(\mathrm{ROI})}$ & 93.10 & 143.74 & 133.63 & 159.02 \\
\hline & $A_{(\text {roi })}$ & 236.03 & 248.13 & 272.43 & 285.21 \\
\hline \multirow[t]{4}{*}{ The middle } & $\mathrm{C}_{(\mathrm{ROI})}$ & 82.66 & 78.24 & 73.05 & 84.49 \\
\hline & $\mathrm{C}_{(\mathrm{roi})}$ & 202.84 & 228.97 & 225.78 & 228.49 \\
\hline & $\mathrm{A}_{(\mathrm{ROI})}$ & 85.55 & 89.97 & 99.90 & 122.79 \\
\hline & $A_{(\text {roi })}$ & 222.63 & 287.33 & 268.85 & 255.60 \\
\hline \multirow[t]{4}{*}{ The ring } & $\mathrm{C}_{(\mathrm{ROI})}$ & 74.70 & 70.43 & 67.08 & 76.46 \\
\hline & $\mathrm{C}_{(\mathrm{roi})}$ & 197.47 & 189.34 & 197.27 & 207.97 \\
\hline & $\mathrm{A}_{(\mathrm{ROI})}$ & 71.46 & 79.98 & 86.22 & 91.49 \\
\hline & $A_{(\text {roi })}$ & 71.46 & 79.98 & 86.22 & 91.49 \\
\hline \multirow[t]{4}{*}{ The little } & $\mathrm{C}_{(\mathrm{ROI})}$ & 87.50 & 79.16 & 65.42 & 67.49 \\
\hline & $\mathrm{C}_{(\mathrm{roi})}$ & 159.64 & $|50.5|$ & $|39.3|$ & 143.33 \\
\hline & $\mathrm{A}_{(\mathrm{ROI})}$ & 71.20 & 80.51 & 93.67 & 83.03 \\
\hline & $A_{(\text {roi })}$ & 137.39 & 130.93 & 126.78 & 151.73 \\
\hline \multirow[t]{2}{*}{ Fingers } & \multirow[t]{2}{*}{ Area } & \multicolumn{4}{|c|}{ Temperature $\left({ }^{\circ} \mathrm{C}\right)$} \\
\hline & & $\mathbf{t}_{\mathbf{0}}$ & $\mathbf{t}_{\mathbf{l}}$ & $t_{2}$ & $\mathbf{t}_{3}$ \\
\hline \multirow[t]{4}{*}{ The index } & $\mathrm{C}_{(\mathrm{ROI})}$ & 35.56 & 34.39 & 34.33 & 34.50 \\
\hline & $\mathrm{C}_{(\text {roi })}$ & 35.86 & 35.49 & 35.72 & 35.78 \\
\hline & $\mathrm{A}_{(\mathrm{ROI})}$ & 35.84 & 35.33 & 35.94 & 36.01 \\
\hline & $A_{(\text {roi })}$ & 35.51 & 35.76 & 35.95 & 36.32 \\
\hline \multirow[t]{4}{*}{ The middle } & $\mathrm{C}_{(\mathrm{ROI})}$ & 35.60 & 34.45 & 34.51 & 34.72 \\
\hline & $\mathrm{C}_{(\mathrm{roi})}$ & 35.95 & 35.54 & 35.81 & 35.80 \\
\hline & $\mathrm{A}_{(\mathrm{ROI})}$ & 35.76 & 34.97 & 35.80 & 36.09 \\
\hline & $A_{(\text {roi })}$ & 35.74 & 36.13 & 36.34 & 36.17 \\
\hline \multirow[t]{4}{*}{ The ring } & $\mathrm{C}_{(\mathrm{ROI})}$ & 36.09 & 35.83 & 35.64 & 35.84 \\
\hline & $\mathrm{C}_{(\mathrm{roi})}$ & 36.43 & 35.78 & 35.95 & 35.82 \\
\hline & $\mathrm{A}_{(\mathrm{ROI})}$ & 35.77 & 35.94 & 36.01 & 35.93 \\
\hline & $A_{(\text {roi })}$ & 36.47 & 36.34 & 36.44 & 36.25 \\
\hline \multirow[t]{4}{*}{ The little } & $\mathrm{C}_{(\mathrm{ROI})}$ & 36.25 & 35.86 & 35.26 & 35.23 \\
\hline & $\mathrm{C}_{(\text {roi })}$ & 36.47 & 35.89 & 36.15 & 35.95 \\
\hline & $\mathrm{A}_{(\mathrm{ROI})}$ & 35.73 & 35.71 & 35.49 & 35.63 \\
\hline & $A_{(\text {roi })}$ & 36.78 & 36.45 & 36.39 & 36.31 \\
\hline
\end{tabular}

Abbreviations: $\mathrm{C}_{(\mathrm{ROI})}$, region on the nail bed of the fingers on the contralateral side; $\mathrm{C}_{(\mathrm{roi})}$, region on the skin just proximal to the fingers on the contralateral side; $A_{(R O I)}$, region on the nail bed of the fingers on the blocked side; $A_{(\text {roi })}$, region on the skin just proximal to the fingers on the blocked side.

the forearm taken at $t_{3}$ showed that there was an apparent discrepancy between C6 and C8 innervation areas (Supplementary Figure 1). Related data are shown in Table 1 and Figure 4.

\section{Discussion}

With the innovation of ultrasonic imaging technology, ultrasound-guided nerve root injections have achieved significant progress. The adjacent tiny structures around the foramina, such as nerves and vessels, can be easily distinguished to avoid intravascular injection during the procedure. ${ }^{9,10}$ Moreover, it has become the first choice to make treatment targeting a selective cervical root block directly or a relevant cervical epidural space. ${ }^{11,12}$ In the present case, the patient with cervical radicular pain restricted to dermatomes of $\mathrm{C} 6, \mathrm{C} 7$, who showed limited symptom remission to physical therapy and the use of oral anti-inflammatory agents/analgesics previously, gained further pain relief during 6-month follow up.

In this case, we found that both the BFI and temperature values in ROIs made a noticeable rise on the index and middle fingers after selective $\mathrm{C} 7$ and $\mathrm{C} 6$ nerve root block. It is worth mentioning that the increase was not just limited to the most distal parts of the upper extremity, but also corresponding areas at the forearm. From what has been described above, it is suggested that both LSCI and IT provided the potential to evaluate the effect of SNR. Our case was the first time to investigate the feasibility of combining these two ways to assess the clinical outcomes for SNR at different anatomical levels.

Regional anesthesia, including neuraxial anesthesia and peripheral nerve blocks, can induce vasodilatation by means of temporary elimination of sympathetic innervation, thus increasing local skin blood flow and rising temperature. However, there are no similar reports on whether a selective nerve root block can cause similar effects. A previous study reported that specific blocking of the ulnar and median nerve induced conspicuous increases in corresponding areas of the hand, but specific blocking of the musculocutaneous or radial nerve does not increase temperature reversely. According to the author's explanation, this phenomenon might be attributable to the inhomogeneous opening of arteriovenous anastomoses distribution, and specific sympathetic nerve fibers were only present in the median and ulnar nerves. ${ }^{13}$ As a matter of fact, the fibers from the sympathetic nervous system join the nerve plexus in a complicated and uncertain manner, and the thermographic response after a single distal nerve block might not be straightforward. It is currently unclear whether different anatomical levels would contribute to the response. $^{14}$ 


\section{A: Changes over time of blood flow index (BFI) measured by $\mathrm{LSCl}$}

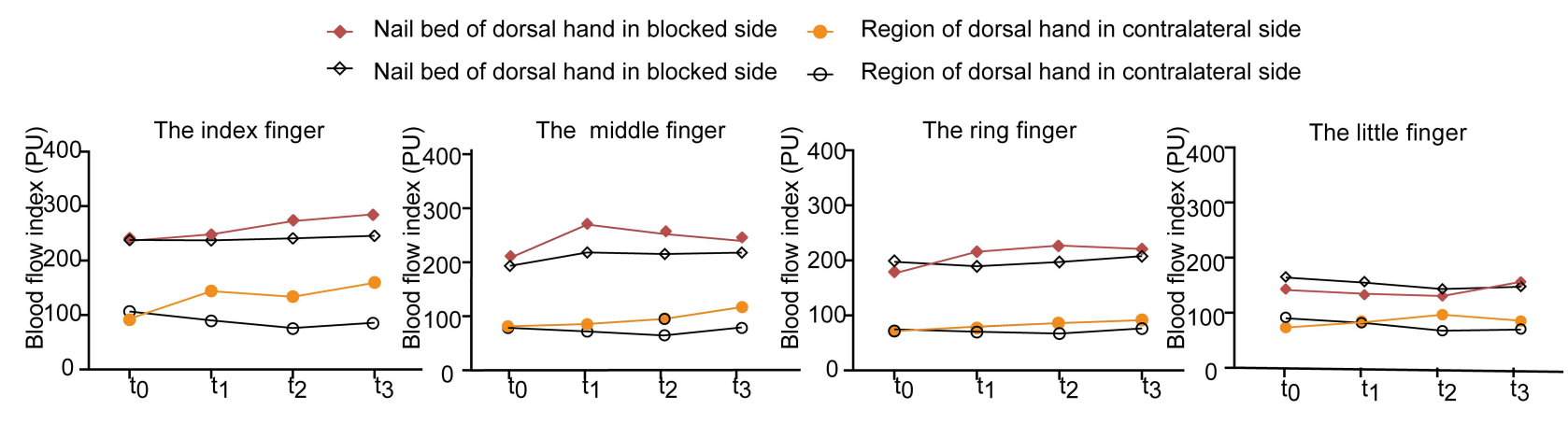

\section{B: Changes over time of temperature $(T)$ measured by IT}

$\checkmark$ Nail bed of dorsal hand in blocked side - Region of dorsal hand in contralateral side

$\diamond$ Nail bed of dorsal hand in blocked side $\quad \diamond$ Region of dorsal hand in contralateral side
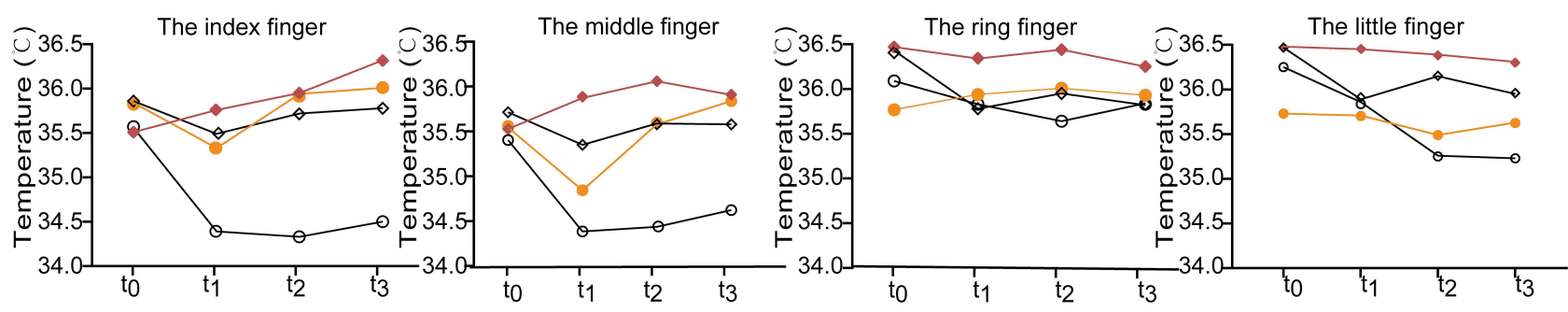

Figure 4 Changes over time of blood flow index (BFl; $\mathbf{A}$ ) and temperature ( $\mathrm{T} ; \mathbf{B})$ values. $\mathrm{t}_{0}$, the baseline value ( 3 min before nerve root block). $\mathrm{t}_{1}, 3$ min after the $\mathrm{C} 7$ block. $t_{2}, 3$ min after the $\mathrm{C} 6$ block. $t_{3}, 20$ min after all the procedure (symptoms assessment).

Therefore, it is necessary to verify the validity of this explanation and figure out what is the difference between proximal SNR and distal nerve blocks in further studies. Due to our previous study, the LSCI technique could be employed to predict the effect of sciatic nerve block in clinical practice. ${ }^{16}$ But the application of this technique in the upper limb needs to be confirmed since the composition and distribution of vascular nerves in upper or lower extremities differ. ${ }^{14}$ The BFI value got the biggest rise after the $\mathrm{C} 7$ nerve root block in the innervated area (nail bed of the middle finger), which was similar to the one after $\mathrm{C} 6$ nerve root block in the innervated area (nail bed of the index finger). The result appeared as potential confirmation of a proper nerve root blockade effect, consistent with our expected result.

It has been a long time for skin temperature as an indicator of regional anesthesia success. Compared with the BFI value, it could be a little confusing for the thermographic response. That might be explained as a result of the heat conduction of adjacent fingers since they did not splay out. In addition, our observation window (3 $\mathrm{min}$ after each SNR) could account for part of the discrepancy, with temperature changes lagging behind the blood flow.
Ultrasound images only provide a two-dimensional view of a single cross-section, making it sometimes difficult to determine the correct spinal level when performing selective cervical nerve root blocks, although the characteristic images of $\mathrm{C} 7$ and $\mathrm{C} 6$ transverse processes have been used as landmarks. In addition, appearances of a transverse above $\mathrm{C} 6$ level can be similar. If selective nerve root block is used for diagnostic purposes, it is paramount that the correct level is blocked. An objective way to assess the level of nerve roots in addition to ultrasound images would be clinically valuable. Our study, although very preliminary, provides a potential way to help assess the level of block after the procedure.

There are several limitations in this case. Firstly, we cannot rule out the accidental phenomenon of this case. Only larger sample sizes might permit clarification of particular characteristics of therapeutic SNRBs in nonsurgical treatment. Secondly, the injectant mixed solution volume we used, $2.5 \mathrm{~mL}$, allowed the possibility of spreading into the intraformational epidural space. ${ }^{15}$ Thirdly, it is generally accepted that topical administration corticosteroids, local anesthetic agents or their 
combination have demonstrated anti-inflammatory properties to reduce neural dysfunctions. We do not know precisely which factor is responsible for the therapeutic effect. $^{17}$

\section{Conclusion}

In summary, this case suggested that there is a role for selective nerve root block in the nonsurgical treatment of cervical radicular pain. The findings demonstrated that SNRB therapy helped to gain pain relief quickly and that the efficacy would continue for at least 6 months. It is our expectation that treatment feedback at the initial presentation and the changes of blood flow and temperature in the corresponding innervated region after treatment could provide clues about the likelihood of future outcomes.

\section{Funding}

This report was funded in part by Grant 81873793 to Wei Mei from the National Natural Science Foundation of China (NSFC).

\section{Disclosure}

The authors report no conflicts of interest in this work.

\section{References}

1. Radhakrishnan K, Litchy WJ, O'Fallon WM, Kurland LT. Epidemiology of cervical radiculopathy. A population-based study from Rochester, Minnesota, 1976 through 1990. Brain. 1994;117(Pt 2):325-335. doi:10.1093/brain/117.2.325

2. Tanaka N, Fujimoto Y, An HS, Ikuta Y, Yasuda M. The anatomic relation among the nerve roots, intervertebral foramina, and intervertebral discs of the cervical spine. Spine. 2000;25(3):286-291. doi:10.1097/00007632-200002010-00005

3. Cyteval C, Thomas E, Decoux E, et al. Cervical radiculopathy: open study on percutaneous periradicular foraminal steroid infiltration performed under CT control in 30 patients. AJNR Am J Neuroradiol. 2004;25(3):441-445.

4. Bush K, Hillier S. Outcome of cervical radiculopathy treated with periradicular/epidural corticosteroid injections. Pain Med. 2015;16 (12):2414-2415. doi:10.1111/pme.12709
5. Narouze SN, Vydyanathan A, Kapural L, Sessler DI, Mekhail N. Ultrasound-guided cervical selective nerve root block: a fluoroscopy-controlled feasibility study. Reg Anesth Pain Med. 2009;34(4):343-348

6. Rege A, Murari K, Li N, Thakor NV. Imaging microvascular flow characteristics using laser speckle contrast imaging. Conf Proc IEEE Eng Med Biol Soc. 2010;2010:1978-1981.

7. Wright CI, Kroner CI, Draijer R. Non-invasive methods and stimuli for evaluating the skin's microcirculation. J Pharmacol Toxicol Methods. 2006;54(1):1-25. doi:10.1016/j.vascn.2005.09.004

8. Martinoli C, Bianchi S, Santacroce E, Pugliese F, Graif M, Derchi LE. Brachial plexus sonography: a technique for assessing the root level. AJR Am J Roentgenol. 2002;179(3):699-702.

9. Greher M, Moriggl B, Curatolo M, Kirchmair L, Eichenberger U. Sonographic visualization and ultrasound-guided blockade of the greater occipital nerve: a comparison of two selective techniques confirmed by anatomical dissection. Br $J$ Anaesth. 2010;104 (5):637-642. doi:10.1093/bja/aeq052

10. Gofeld M. Ultrasonography in pain medicine: a critical review. Pain Pract. 2008;8(4):226-240. doi:10.1111/j.1533-2500.2008.00215.x

11. Zhang X, Shi H, Zhou J, et al. The effectiveness of ultrasound-guided cervical transforaminal epidural steroid injections in cervical radiculopathy: a prospective pilot study. J Pain Res. 2018;12:171-177. doi:10.2147/JPR.S181915

12. Boswell MV, Trescot AM, Datta S, et al. Interventional techniques: evidence-based practice guidelines in the management of chronic spinal pain. Pain Physician. 2007;10(1):7-111.

13. Lange KH, Jansen T, Asghar S, Kristensen PL, Skjønnemand M, Nørgaard P. Skin temperature measured by infrared thermography after specific ultrasound-guided blocking of the musculocutaneous, radial, ulnar, and median nerves in the upper extremity. Br J Anaesth. 2011;106(6):887-895. doi:10.1093/bja/aer085

14. Woollard HH, Weddell G. The composition and distribution of vascular nerves in the extremities. J Anat. 1935;69(Pt2):165176.3 .

15. Kang S, Yang SN, Kim SH, Byun CW, Yoon JS. Ultrasoundguided cervical nerve root block: does volume affect the spreading pattern? Pain Med. 2016;17(11):1978-1984. doi:10.1093/pm/pnw 027

16. Wu X, Li J, Joypaul K, et al. Blood flow index as an indicator of successful sciatic nerve block: a prospective observational study using laser speckle contrast imaging. Br J Anaesth. 2018;121 (4):859-866. doi:10.1016/j.bja.2018.05.065

17. Baron R, Schattschneider J, Binder A, Siebrecht D, Wasner G. Relation between sympathetic vasoconstrictor activity and pain and hyperalgesia in complex regional pain syndromes: a case-control study. Lancet. 2002;359(9318):1655-1660. doi:10.1016/S0140-6736 (02)08589-6
Journal of Pain Research

\section{Publish your work in this journal}

The Journal of Pain Research is an international, peer reviewed, open access, online journal that welcomes laboratory and clinical findings in the fields of pain research and the prevention and management of pain. Original research, reviews, symposium reports, hypothesis formation and commentaries are all considered for publication. The manuscript management system is completely online and includes a very quick and fair peer-review system, which is all easy to use. Visit http:// www.dovepress.com/testimonials.php to read real quotes from published authors. 